\title{
4 \\ Creative Leadership: The Agency of the NESB Artist
}

Australia's multicultural society is yet to be adequately reflected through its art. Although many artists may be ambivalent about labels such as 'multicultural' or 'NESB' or 'CALD', it is they who contribute significantly to an arts scene that engages with the diversity of Australia's population, which in turn generates the space and provenance for further possibilities of a supportive multicultural arts milieu. As the previous chapters demonstrate, the extent of the challenges and barriers faced by non-English speaking background (NESB) artists in Australia means that there is a limited multicultural arts milieu here. In this and the following two chapters, I argue that consistent, creative and organisational leadership in culturally diverse arts production and presentation will produce a flourishing milieu. The artists who show distributed, transformative and charismatic leadership enable the milieu to creatively expand. Creative leaders are individual practitioners who push artistic boundaries and, by doing so, provide inspiration and opportunities for other artists.

Ideally, a multicultural arts milieu is one in which artists are located in, and examine, the 'shifting and entangled diversities' (Ang 2011,788) and 'practices of exchange' that 'facilitate the continuation of intercultural relations' (Noble 2009, 51). Such a milieu expands the notion of the 'diasporic spaces within which much of the contemporary arts were produced by the so-called NESB artists' (Rizvi 2003, 231). My use of the idea of a multicultural arts milieu aims to capture and convey the 
creative, intellectual, social and multicultural context within which mainly NESB artists produce their work. Ideally, it nourishes and sustains the continuation and development of their practice. The role of creative leadership is essential to forging a supportive milieu and, vice versa, the milieu is essential to fostering effective leadership.

This chapter discusses the claim that new modes of creative leadership develop despite, or perhaps in part from, systemic constraints that respond to 'cultural diversity as an inescapable interactive context' (Mar and Ang 2015, 8). Those artists who respond to the opportunities of cultural diversity show creative leadership that builds a multicultural arts milieu. The issues and opportunities that impact upon their practices in that process include trust, visibility and equitable power in an environment in which, for many, little has changed despite the presence of multicultural policies. Their challenges do not align with research that claims that NESB artists perceive more advantage than disadvantage arising from their backgrounds (Throsby and Petetskaya 2017, 145). The artists I interviewed for this study were most forthcoming about their experiences. The characteristics of creative leadership that emerged include creative and cultural persistence, cross-cultural and intercultural competence, brokering skills, self-starting motivation, and political and social awareness.

The inconsistent attention paid to the arts in multicultural policieswhich, at times, has been directly informed by NESB artists- has been more often eroded by periods of institutional disregard. The barriers to change include a lack of comprehension and recognition by mainstream arts institutions, inconsistent levels of critical engagement by the arts media and the small pool of NESB artists. Despite this pattern of systemic instability, the 11 artists I interviewed successfully produce work even though the majority experience tensions arising from their ethnic identities. Rather than see this solely as a burden, they use it as a creative spur to make creativity from friction, establish trust through legitimacy, and develop support and networks. The theme of creativity from friction captures the constraints of being typecast or limited by one's background, issues of creative and cultural autonomy, and intercultural practice. Establishing trust works to address constraints around opportunities for progression, such as critical appraisal and funding. Developing 
support and networks addresses family matters and combats cultural and geographic isolation —all of which contribute to developing a more sustaining multicultural arts milieu.

The artists in this study view their creative production as having the potential to reconfigure the symbols within society. Such ambition shows creative leadership. I describe the intercultural performances of Annalouise Paul to amplify the challenges and persistence of the artist. While this may seem to be overstating the effect of a (usually) small art project often relegated to the sidelines, such incremental contributions reflect the possibility of a more significant transformation.

\section{Creativity from Friction}

The theme of friction and its role in generating creativity emerged through accounts of the constraints interviewees experienced, including the lack of change in the arts sector exemplified by the typecasting of artists in terms of their background. The processes of intercultural practice and negotiation for creative and cultural autonomy reflect how artists respond to those constraints. As discussed earlier, in writing of 'contingent encounters', Tsing $(2005,4-5)$ suggests how cultures can change through 'new arrangements of culture and power'.

Many NESB artists pursue and negotiate 'new arrangements of culture and power' against the odds. The creative openness of unpredictability (the contingent) is used to generate possibilities of exchange whereby artists take the responsibility to increase the level of culturally diverse creative production, making meaning from the 'friction' they experience when navigating the contestations of multicultural Australia. As Gunew (2017b, 37) comments, they are 'dwelling on the small negotiations of everyday sociality' to germinate and develop creative benefits. Those small negotiations form part of the artist's ability to create opportunities despite their experience of low levels of change in the arts world. 


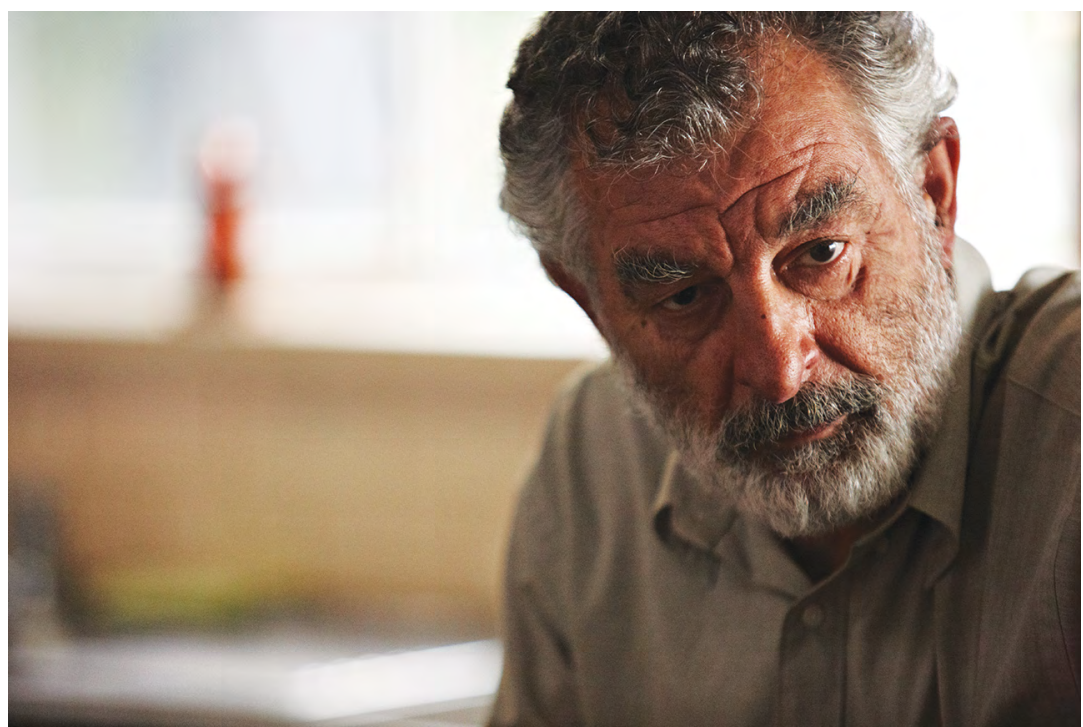

Image 5: Lex Marinos, The Slap, 2011

Photographer: Ben King

Courtesy: Matchbox Pictures

\section{Stasis}

The paradoxes of inclusion in multicultural Australia may stifle aspects of a dynamic cultural life, as Australia's creative potential is yet to match the 'richness of intercultural encounters in contemporary suburban settings' (Noble 2009, 48). There appears to be major obstacles across the arts sectors specific to NESB artists; however, change can and has occurred elsewhere in other areas of 'diversity' in the arts. Film director Rachel Perkins, for example, sees that Indigenous film and arts have achieved parity in Australia, but she sees little change for NESB artists, in particular for Asian-Australian artists (Radio National 2017). Lex Marinos, the most experienced research participant in this study, is a performer, presenter, writer and director for screen, stage and radio (Marinos 2014) (see Image 5). Referring to the stagnancy of multicultural arts over the past 45 years, Marinos (2015, interview) observes that:

I thought as a nation we probably had matured to be much more reflective of the society we have. And it's not so. You don't see it on our main stages, and you certainly don't see it on our TV and film. 
According to Marinos, the arts' ability to reflect multicultural society is still in its infancy and society is the poorer for it. A more mature arts industry, he suggests, would be able to express the richness of cultural diversity and would learn from a historical perspective to enable change. Annette Shun Wah, the director of the Contemporary Asian Australian Performance (CAAP) group, interprets the prevalent history of typecasting as being in stasis:

When I look back now and compare [to the 1980s], it's still the case that people of Asian background don't get roles on television or the stage, or are limited to very few specific stereotypical roles. (A. Shun Wah 2015, interview)

Both Marinos and Shun Wah express frustration and a lack of 'satisfaction' with their respective careers based on visibility. Marinos, who has made these points a number of times, finds the lack of change exasperating. But he does not 'want to be that whingeing wog'; he worries that his complaints would be too irritating and a cause for discomfort by the mainstream art world. The 'whingeing wog' or the 'irritant' experiences the problem repeatedly and experiences also the friction characterised by banging one's head against a 'brick wall'. As the complainant, Marinos steadily grinds against the status quo, needing more persistence as institutional resistance increases (Ahmed 2012, 26). The lack of change over so many decades in the performing arts suggests avoidance of difference has become institutionalised. Marinos embodies the way the creative leader continues to articulate the issues of representation because diversity can only be considered as part of the status quo 'when it ceases to cause trouble' (Ahmed 2012, 27). However, a multicultural arts milieu characterised by the persistent call for change may not want to cease causing trouble. The inquisitive and diverse art practices that could emerge from the dynamic nature of migration patterns to Australia may see both welcome and challenging opportunities for creative disruption.

One of the issues for the arts in a multicultural Australia is the need to recognise it as an ongoing project that responds to the issues and opportunities of the day. It is not something to be solved at a single point in time. Gunew $(1994,1)$ makes a different point about 'trouble' and the politics of attitudinal change, whereby 'politicians cannot afford to be too out of step with public opinion, whereas artists cannot afford not to be'. The role of the artist, therefore, is to continually question and shift the status quo where possible. 


\section{Typecast: 'Send Us an Asian, a Greek or Something'}

Typecasting and stereotyping, often based on appearance, exemplify the lack of change. Being typecast, stereotyped, cast in minority roles or not cast at all is a longstanding issue for NESB actors in theatre and screen in Australia (Bertone, Keating and Mullaly 1998, xi). The 1998 SBS documentary series $A$ Change of Face dealt with 'the conspicuous absence of diversity on Australian screens' and was acclaimed for critiquing how people from 'non-Anglo Celtic backgrounds were ignored, stereotyped and miscast' (Ang, Hawkins and Dabboussy 2008, 164-65). To counter the lack of diversity seen on television, SBS produces contemporary drama narratives with 'migrants and their stories at the centre of the action' (Ang, Hawkins and Dabboussy 2008, 138). Nevertheless, a lack of opportunity remains the common experience for many NESB actors (Screen Australia 2017). Lewis $(2007,41)$ likens the frequency (or lack thereof) of NESB actors cast in minority roles to the spatial marginalisation of ethnic groups in cities'. Linking these two forms of cultural and spatial ghettos crystallises the sense of being barely visible. The slow pace of change regarding representation is a 'glacial' friction that steadily grinds away to eventually alter the landscape. The outer edges (or margins) at times move more quickly and generate greater heat to change the landscape, while the centre (or the mainstream) moves far more slowly. The pertinent simile, whether as an artist or a spokesperson, is that the margins 'melt' (burnout) more readily but also are more dynamically productive than the static centre. Marinos, an artist with a successful career, is aware of the need for more open, creative opportunities. In over 40 years of performing, he has only ever been cast 'as a wog', and he (unreasonably) blames himself:

If I had been a better actor, perhaps I could have surmounted the systemic impediments. Yet, I do find it curious that every 10-15 years there is a call for more colour-blind casting and more diverse artists. (L. Marinos 2015, interview)

The repetitive nature of the calls for greater inclusion both indicate the lack of change and affirm the role of the arts in representing the diversity of Australians. Marinos (2015, interview) questions whether decisionmakers with the power to program are best equipped to deliver arts programs that capture Australia’s diversity: 
I wasn't prepared for the fact that it would be as difficult as it was and still is, as a NESB artist. When I was starting out, there were also two other young actors from Greek backgrounds. I would get called George or Nick, who were the other two guys, and they would get called Lex. It suddenly occurred to me that as far as casting directors went, we were interchangeable. We were wogs.

Marinos's experience in 1970 echoes that of Annalouise Paul in 2015. Paul is a dancer, choreographer and actor who has been practising internationally for over 30 years, uncovering her cultural heritage of 'two strains of Jewish' through her Sephardic father and Ashkenazy mother. Paul recalls her early experiences with actors' agents saying 'well, you're only ever going to get cast as an ethnic', and not knowing what that meant. In London, she was cast as Indian and in Los Angeles as Indian, Italian and Filipino. Back in Australia, being typecast remains an issue:

As an actor, it's pretty much the same as it was 30 years ago. Two weeks ago [May 2015] an agent sent through a casting brief which was - can you send us 'an Asian, a Greek or something, not Caucasian’ [laughs]. (A. Paul 2015, interview)

Actors such as Marinos and Paul experience a form of invisibility in a career based on visibility. They are not recognised as their individual selves by agents and, therefore, are not valued as individual performers. Within a 'star'-focused industry, this lack of valuing raises questions as to whether the arts system is able to open up sufficiently to support them.

Paul's experience highlights questions about who decides what diversity on screen looks like and how it should be represented. A casting agent saying 'send us an Asian, Greek or something' expresses disinterest and implies a very crude understanding of cultural heritages. To be compliant with calls for diversity involves meeting 'minimal requirements', whereas fulfilling the requirements moves beyond compliance (Ahmed 2012, 106). Compliance can lead to tokenism- 'just ticking the box'-a disengaged response that is frequently identified with multiculturalism in the arts. Australia does not have 'quotas' for diverse casting or content, so there are no boxes to tick (apart from those that gather data for grant statistics).

Despite this, the 'box' continues to be seen as a 'potent contested symbol', as it represents a range of responses to calls for change in the arts industry. It is seen by some as diminishing the creative work of NESB artists and by others as an appropriate tool for affirmative action, and is commonly used by those who lack an understanding as to how the work 'fits into the 
larger artistic landscape' (Castagna 2017). When it diminishes the creative output or is not understood, 'ticking the box' produces a constraining friction. By contrast, when it is seen as useful to affirm diversity, the 'tick' can generate a productive form of friction. As with successful targets for gender equity, the litmus test would be whether an affirmative quota would contribute to a supportive multicultural arts milieu.

The industry claims a lack of professional actors as the reason for the lack of diversity. Such claims are often followed by calls for more training (Castagna 2017). Marinos (2015, interview) trains acting students from diverse ethnic backgrounds whose experience, he says:

Is pretty brutal because they find it difficult to get an agent, and when they do, they're told that there's nothing for them. Or they might get rung up to play a greengrocer or a taxi driver or a terrorist or something. But they won't play the doctor or the lawyer or the boy next door.

This resistance from industry means NESB actors require persistence and self-confidence to proactively erode some of the small cracks and demonstrate creative leadership to make a change for themselves and for others. Ahmed $(2012,199)$ analyses the brick wall of resistance as an 'institutional limit' that is invisible until encountered. Artists are aware of the imposed limits often expressed as the wall or a 'closed door'. Writer and radio broadcaster Sunil Badami (2017) urges NESB artists to 'make a new door' because, for him, persistent attempts to break through existing doors are no longer worth the effort. Making a new door in this sense invokes the agency and creative leadership of the individual practitioner to forge new pathways for themselves and, importantly, for others. The value in the networking forums at which Badami speaks is that the solutions, regardless of their apparent simplicity, are shared among the artists present, validating their individual experiences and leveraging positive group responses. This is a form of relational leadership that builds from a set of relations and expands to influence others to achieve the aims of the group. 


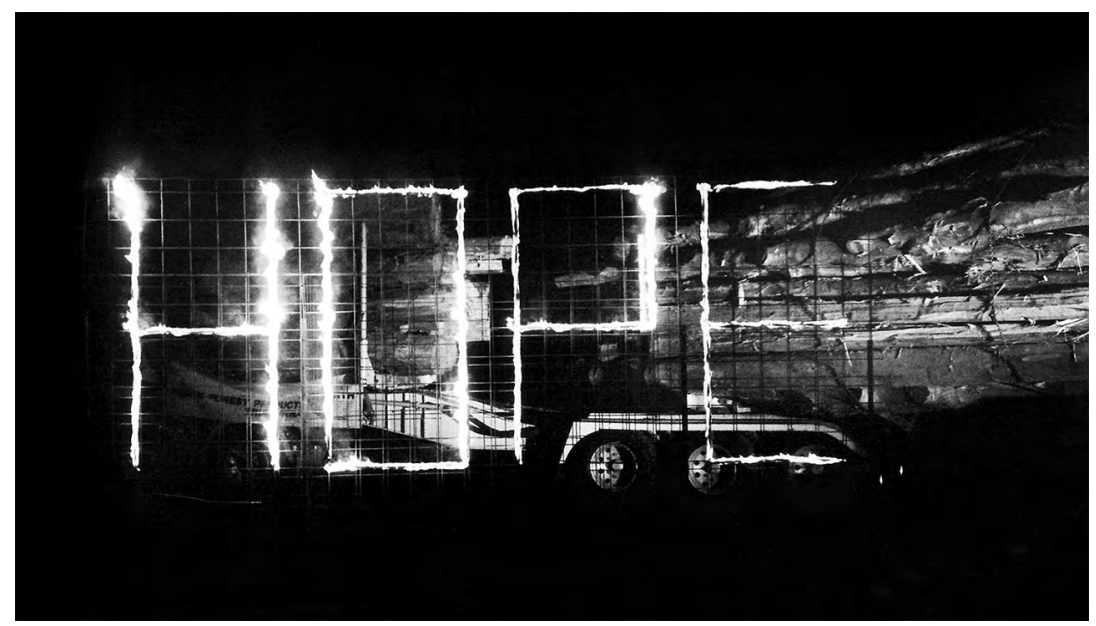

Image 6: Konstantin Koukias, Sea Chant. Settlers, Ships and Saw-Horses, 2001

Photographer: Lucia Rossi

Courtesy: Ten Days on the Island Festival

\section{A Crack in the Doorway}

Not all doors are firmly closed. Konstantin Koukias, a 'Greek-Tasmanian composer', trained at the Tasmanian and Sydney conservatoriums for music. He is the artistic director of an innovative small opera company, IHOS Opera (see Image 6), now based in Amsterdam. He accepted the advice of mentors as to the creative opportunities afforded by his Greek background:

Peter Sculthorpe said to me: 'Konstantin if you want to become a composer you should use your Greek heritage to give yourself a point of difference'. So I started to study Byzantine church music. (K. Koukias 2015, interview)

Sculthorpe, an Australian composer, positioned Koukias within his ethnic minority-a move akin to typecasting. He also elevated this minority, seeing it as one with unique creative potential—a 'reified category of ethnicity' (Noble 2011, 830). The potential of ethnic artistic heritage to act as a creative 'point of difference' gives rise to a form of creative cosmopolitanism through a bicultural practice that hybridises, in this example, the traditional Byzantine with contemporary composition. In Koukias's case, the work appears purposefully reified and elite. At the same time, it is also accessible to the public, which accommodates the 
broader cultural processes of 'people-mixing' that contribute to an 'everyday cosmopolitanism' (Noble 2011). This capacity for an artistic 'avant-garde' (at the forefront of new processes) to be relevant to culturally diverse audiences brings the work into an everyday dialogue that contributes to a vibrant multicultural arts milieu. Koukias is recognised by his peers for his contribution but it remains to be seen whether his work will enter the Australian artistic vernacular.

Koukias was able to turn his cultural background to creative advantage and has had a 'supportive and positive experience' as an artist. However, he has also experienced conflicting expectations as to how he should position himself within the multicultural arts context by fellow Greeks. He describes the reception of his 'breakthrough piece' (Westwood 2017), Days and Nights with Christ (1990), which is based on his brother's experience with schizophrenia:

That's what launched the company. IHOS is Greek for 'sound'. People were coming up to me, mainly Greek people, saying 'how come you're in a mainstream festival? You should be in a multicultural festival'. (K. Koukias 2015, interview)

These conflicting expectations constitute a form of 'friction': one pushes into notoriety in the mainstream and the other pushes against the low profile of the multicultural tributary. These frictions may also characterise the career of the NESB artist. Koukias manages to keep them in balance, his heritage and family history joining unusual or unfamiliar forms in contemporary classical repertoire. This form of bicultural hybridity is fairly well established now, but in 1990 it was experimental. The push-pull of who should 'own him'-the multicultural or the mainstream festivalsuggests a sense of loss on the part of the multicultural programmer struggling to gain an audience and funding traction through the inclusion of contemporary, challenging work. Koukias, in extracting opportunities from creative tensions and establishing his own experimental opera company, demonstrates creative leadership.

\section{Stereotypes from beyond Centre Stage}

Opportunities for creative expression are further complicated when geographical location is intertwined with ethnicity. Forceful friction, which can be understood as striving against barriers in theatre and film, tries to break through the issue of whose voice is heard and which artists 
make the work. The Finished People (IMDb 2003), directed by Khoa Do, is an independent low-budget film about youth homelessness in the Western Sydney suburb of Cabramatta. It is often cited by people from the area as having its own 'voice' as distinct from being made by directors from 'places like the Eastern Suburbs or with a bit more money who would monopolise those stories and speak on behalf of us' (S. Ly 2015, interview). Vinh Nguyen, a 24-year-old freelance videographer who studied at University of Technology Sydney and whose parents came to Australia as Vietnamese refugees, wants more control over the narratives:

I don't want to talk to my parents about the war, what was being a boat person like? I think that's degrading. It was a tough time, and we will never forget what happened in 1975. They've been here for 30 years, it's time to create new memories and experiences. (V. Nguyen 2015, interview)

Nguyen had been freelancing for five years, mainly on Western Sydney community arts projects, and, in 2015, received his first local government community arts grant of $\$ 4,000$ :

I never thought of myself as multicultural. I identify very strongly with Western Sydney, and that equates with multicultural. It is such a mouthful to say: I am a multicultural artist from Western Sydney. I just say I am from Western Sydney. (V. Nguyen 2015, interview)

Nguyen expresses confusion and dismay at the array of labels that could be attached to him. Western Sydney has a high proportion of NESB artists (Hanna 2012, 5) and several arts centres that activate their culturally diverse artist populations (Knight 2013). The majority of artists who live in Western Sydney identify proudly with their location; they see it as a badge of honour (Stevenson et al. 2017, 15). Nguyen exemplifies how NESB artists often navigate their identity around labels to suit their situation. The belief that because he is ethnically different he is therefore 'multicultural' reinforces his experience of being 'other' when outside his home. Nevertheless, he navigates those borders, applying self-restraint to remain mute in the face of taunts about his Bankstown (an outer suburb of Western Sydney) home:

Immediately it's jokes about getting shot, getting stabbed. You know, racism types. And it sucks but I'm forced to smile sometimes, just to keep any opportunity for jobs. Or make a slight in-joke about it. (V. Nguyen 2015, interview) 
Nguyen's perception that he might be accepted if he represses a jarring retort to the racist slur is an example of a reverse form of 'tolerance' on the part of the 'tolerated', another familiar experience. As Hage (2000, 87) points out, the intention behind multicultural tolerance is a form of 'symbolic violence' whereby 'domination is presented as a form of egalitarianism'. The Sydneyites consider themselves to be in a position of power (the in-group) and assume that they can make jokes at Nguyen's expense. Further, they assume that there will be no retort, because Nguyen, who is trying to extend his career into Sydney, is not in a position of power. These exchanges can be viewed as friction-an unwritten, yet scripted, interaction of 'banter' to accommodate Nguyen.

Reading Nguyen's comments on networking as an example of 'everyday cosmopolitanism' positions them as 'situated and strategic practices of transaction in specific contexts' (Noble 2009, 46). The exchanges between Nguyen and his potential colleagues are strategic within a shared context of arts networking in the urban centre of Sydney. The banter tests the potential for relationships through a form of friction akin to slipping and rolling that generates momentum. Such exchanges also demonstrate the paradox of multicultural Australia, whereby those of diverse cultural backgrounds can experience inclusion and exclusion simultaneously (Ang, Brand and Noble 2006, 19-21).

Regardless, Nguyen's agency remains active, as he possesses aspects of the 'insider'. He knows when and where to attend freelance media networking events in Sydney and does not suggest that he is ignored. He displays traits of the 'creative aspirant' who requires an 'awareness of, and ability to play with, the symbolic codes around style and taste within youth-based, subcultural creative scenes to increase their chances of success in the creative industries' (Idriss 2018, 71). Nguyen networks as a self-employed media artist who experiences the socio-economic disadvantages associated with Western Sydney. He associates creative freedom as a benefit of living in Western Sydney in both 'aesthetic risk-taking and cultural difference' (Stevenson et al. 2017, 15). His aspirations are equivalent to many of the sole trader, creative entrepreneurs who have a pragmatic approach to generating income from their 'creative' enterprises, and who manoeuvre their careers to earn a 'decent' living rather than 'retain some romantic association with "arts for art's sake"' (Idriss 2018, 97). 
Three generations of actors, Marinos, Shun Wah and Paul, share experiences of invisibility. Koukias and Nguyen are one generation apart and share similar class and isolated geographical backgrounds. They are, however, at different historical and creative places within the arts spectrum. Koukias successfully employs and promotes the cultural forms of his contemporary classical composition drawn from his Greek heritage, demonstrating experimental multicultural arts practice. Nguyen aspires to become a documentary filmmaker to give 'voice' to his ideas and those of the members of his local community. The more likely trajectory for him will be one of short-term employment contracts and volunteer video work. He seeks freelance work in Sydney and, having received a community arts grant, has not completely abandoned creative aspirations but will begin by taking a 'safer, less risky career path validated from within the ethnic communities' (Idriss 2018, 91). This validation comes from families and community groups and is linked to the capacity to generate income from media production, as distinct from pursuing a more financially uneven career in the arts. Nguyen has had to reconsider his artistic trajectory and is attempting to bridge the gap between Western Sydney and Sydney as a Vietnamese Australian media producer while judiciously navigating within the more familiar spaces of his ethnic community.

\section{Intercultural Practice}

In another part of the multicultural arts milieu is the independent professional artist who adopts an intercultural approach, as discussed in Chapter 1. For the NESB artist, intercultural can mean those who work across aesthetic codes and cultural codes of identity (Idriss 2018, 141). Hossein Valamanesh is an established Iranian-Australian sculptor and painter who exhibits regularly and whose work is included in many Australian visual arts collections (see Image 7). He graduated from Tehran's School of Fine Art Painting before migrating to Australia in 1973, where he completed a fine arts degree at the South Australian School of the Arts:

Multicultural Australia meant that I was able to express certain ideas from that. Those works were very much to do with a different dwelling, different place. And then you bring that otherness to the view of the thing. (H. Valamanesh 2015, interview) 


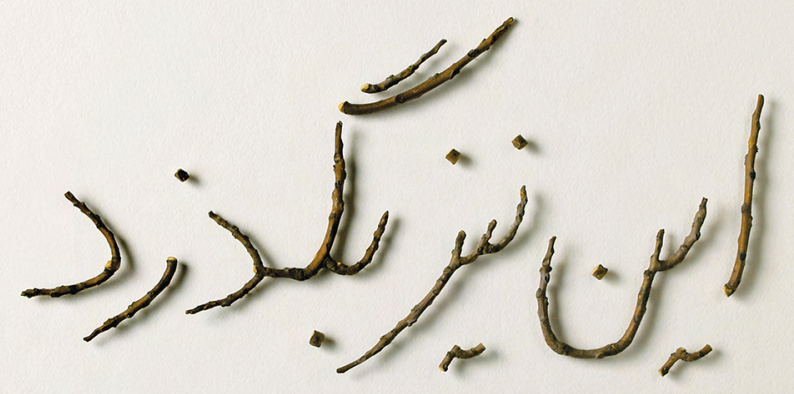

\section{Image 7: Hossein Valamanesh, This Will Also Pass, 2007}

Ailanthus branches on paper, $58 \times 76 \times 2 \mathrm{~cm}$, edition of three

Private collection, Adelaide

Photographer: M. Kluvanek

Valamanesh carefully navigates away from being the 'other' while drawing on its creative potential. He does not see himself as 'other', yet he uses 'otherness' to make work. He has generated a different practice from his 'political art making in Iran' and now takes a calmer 'more personal approach, more to do with emotions and feelings and memory'.

Valamanesh echoes other artists who relocate themselves and their practice, wherein the importance of 'country, longing, belonging and inclusion' are linked with 'memory, history, lived experiences but also imagining the future' (Babacan 2011, 15). His approach draws on aesthetically recognisable forms associated with the Iran of his memory and is intercultural because of inflections relevant to his current context. Valamanesh views his work as having the 'flavour of what I am and where I come from', but he resists Iran as the only touchstone and hopes his ideas go 'beyond the idea of being from one place'. The Lover Circles His Own Heart (2003) (see Image 3), a contemporary sculpture based on the poem of the same name by the thirteenth-century poet Rumi, is an enlivened entanglement. The simple structure of the 'skirt' evokes the whirling dervish, yet, in the dimly lit gallery setting, its disembodied movement 
evokes a ghost-like and graceful reminiscence of the Iranian meditative sacred dance. Another reading of this work is as a futuristic metaphor for tradition and contemporary elisions that question whether the machine can adequately replace the mesmerising intention of the dervish.

Koukias's (2015, interview) intercultural work is also based on cultural symbols, in his case that of family musicology:

I incorporated Byzantine chant in my early works, recording elderly Greek women, including my mother, singing thousands of years old folk songs. I mixed them within contemporary classical genre, incorporating pre-recorded tape and treatment of sounds, words and themes. Cultural, Greek themes.

Both Valamanesh and Koukias demonstrate innovation through enlivened entanglement by sensitively bringing one form of culturally specific traditional expression into dialogue with a new context. This process suggests a careful massaging in vision and sound as a form of cultural brokerage (Kurin 1997). Both Valamanesh and Koukias exemplify creative leadership: the individual practitioner through whom other artists may take succour and inspiration, because they push creative boundaries. As individual artists who have achieved recognition, Valamanesh and Koukias also evoke 'charismatic leadership' because they inspire, drive the project and demonstrate the benefits of creative risk-taking. They are the ones who take, or are given, prime credit, regardless of others who worked on the project. They exemplify creative leadership because they maintain their creative and cultural autonomy, as discussed in Chapter 2. Neither compromises their practice or becomes limited by others' cultural ignorance. Their niche artforms run the risk of staying niche, but their potential to influence art's history and contribute to a multicultural arts milieu outweighs that risk.

Koukias's and Valamanesh's ethnic and cultural heritages were the starting point for their creative practices and fed their success in mainstream arts. Both artists qualify their success; they feel that their careers cannot be too prominent — cannot have too much 'star-quality' - and that they must somehow sit back slightly. Koukias left Australia because he had to: without support from government arts agencies, his practice was stifled. Valamanesh (2015, interview) attributes his success, in part, to staying almost under the radar:

I don't think my work was ever in the hot top ten or whatever. I never became too fast, too famous, too rich. I'm ambitious, but I just felt like things had to come to you as well. 
Valamanesh's reflection demonstrates the quality of persistence and a quiet, yet striving, ambition that steadily edges along. It is possible to read his description as fitting the image of the 'ideal migrant' who contributes to, and 'integrates' into, society, making an advantage of the 'articulation of diverse cultural forms and use of the services of the state to assist him' (Hage 2000, 83-84).

Both artists can also be seen as mediating between 'cultures'. Mar and Ang $(2015,62)$ observe a shift in art processes towards mediation to generate 'understandings of difference and diversity'. Mediation is found in the role of an 'intermediary' (Totaro 1991, 12) or 'cultural broker' (Kurin 1997, 17) and assists in cultural translation. These modes of translation suggest a type of relational leadership or attunement capable of cultural interpretation that builds a flourishing milieu.

Knowledge of the sociopolitical as well as the creative context is essential to transact these relationships, the calibre of which, in this case, requires the artist to be adroit across several positions, not all of which are readily achievable. One is an ethical position about how to produce 'understandings of difference'. Another is the consideration of aesthetics as to what will be produced. Still another concerns the position of the NESB artist-how they will produce the work and where it will be presented to the public. Each of these positions engages in 'practices of cultural translation' (Ang 2003a, 33).

The constraints and opportunities presented through the issues of creative and cultural autonomy complicate the context and working processes of the artist. Trust is implicit yet must be earnt by the artist in the creative context of cultural translation. Trust resurfaces in public presentations of the artwork that involve a different set of structures in the art world.

\section{Establishing Trust through Legitimacy}

The issues of creative autonomy, translation, experimentation and typecasting discussed in the previous section raise issues around trust between the artist and their presenters and critics that inform considerations of legitimacy of the arts sector. Establishing trust will support creative risk-taking that increases the exposure of the artist and their work. Establishing trust encompasses the opportunities artists experience for creative career progression through the 'legitimate' processes of public presentation, published critical writing and funding. The discourse of creative practice typically positions NESB artists within community arts 
sectors (Hawkins 1993, 86-88; Blonski 1994, 199; Idriss 2018, 142) to the extent that multicultural arts have been equated with 'community arts' (Kalantzis and Cope 1994, 142). The result of this perception is that their art is not viewed as legitimate or validated as mainstream or traditional art. This perception persists even though NESB artists have low levels of employment in community arts (DARTS 2017; Throsby and Petetskaya 2017, 30).

There is minimal commentary about the relationship between NESB artists and those arbiters who present and profile artworks in major spaces and events. Within the context of creative leadership, gaining access to arts structures enhances the legitimacy of the artist's work and develops expertise and support for other artists. The roles of intermediaries and cultural brokers become even more important in this phase of the 'culture cycle', as they are the ones who generate pathways into the mainstream (or at least a large tributary) to attain recognition beyond an ethnospecific community audience that can limit creativity if only framed within 'normative communal terms' (Idriss 2018, 153). Being included in art networks that generate trusting creative relationships continues to be identified as an important need (Stevenson et al. 2017, 54). Demonstrating the skills and know-how to generate trust within funding and presenting agencies forms part of the leadership role of the NESB artist because of the public engagement with decision-makers and presenters.

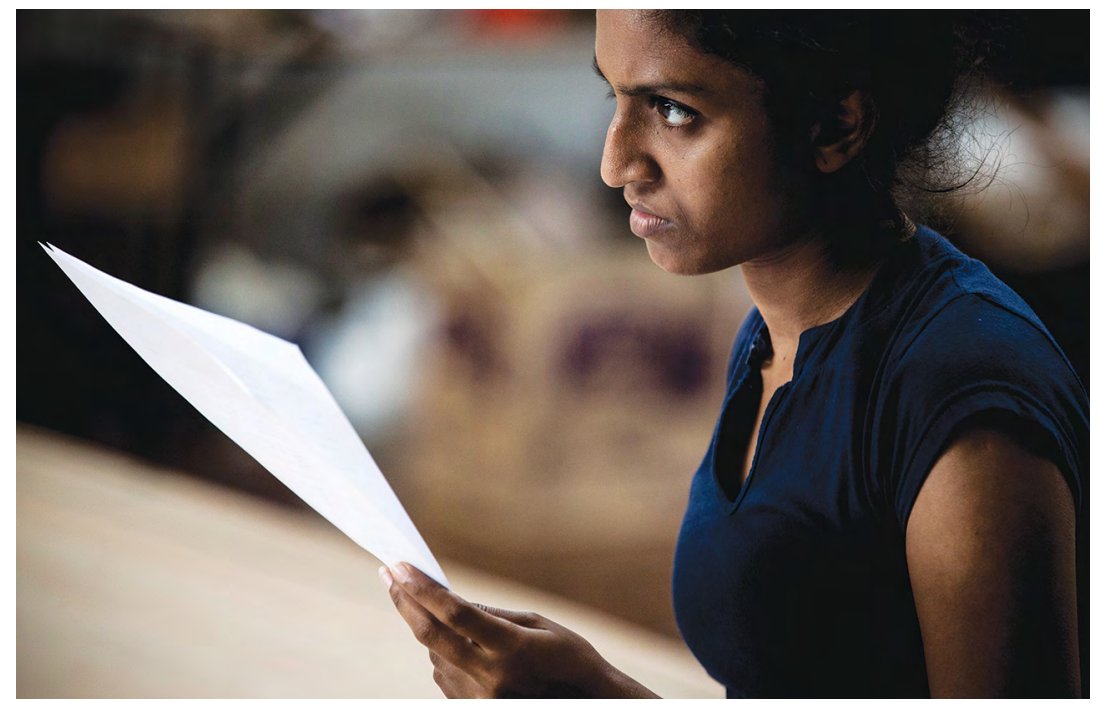

Image 8: Counting and Cracking, Belvoir Street Theatre, 2019

Photographer: (c) Brett Boardman 


\section{The Invisible Milieu}

S. Shakthidharan is a writer, director, musician and composer based in Western Sydney (see Image 8). He was the inaugural executive and artistic director of CuriousWorks, established in 2006 to produce digital media within long-term community projects (CuriousWorks 2021a). CuriousWorks is known for its community engagement programs that utilise digital storytelling processes to evolve the everyday experiences of cultural diversity. Trimboli $(2016,14)$ describes their 'digital interventions [as] a mélange of new media and community-based art practices incorporating aspects of the conventional digital storytelling genre in a fluid fashion'. This 'mélange' led to the successful low-budget feature film Riz, which was programmed in the 2015 Sydney Film Festival and was well received (Morellini 2015). Shakthidharan (2015, interview) suggests that, alongside the visible indicators of stereotypes, there are less visible considerations such as the underlying challenges of the ethical and ethnic contexts for artists who work interculturally:

The initiatives that intend to help artists from multicultural backgrounds never look at all at the surrounding things we have to do to ensure equitable power, to ensure that community respect and cultural understanding [is] done properly. And I feel like unless a policy tackles the full task, then it will always fall short.

The skills to accomplish the 'surrounding things' are rarely made explicit because the types of negotiation, care and responsibility within an ethnospecific or multicultural context are not necessarily part of the arts vocabulary or mindset and can, therefore, be 'invisible'. Artists are not taught how to develop trusting relationships as part of formal creative arts courses. NESB artists are perceived to acquire this capacity informally through their family, peers and, possibly, participation in ethnic community cultural activities. Idriss $(2018,142-43)$ argues that the challenges of creative self-expression (familial, class, geographic and creative isolation) are such that Arab-Australian artists retreat to community arts through "capturing "authentic" stories as representatives or authority figures of the local community', and that this at least generates some control over the stories they produce. To work against these cultural blind spots is a point of tension and a marker of creative leadership, albeit often an invisible one, that requires respect and understanding, based in the development of trusting relationships. 


\section{'I Would Like a Culture in Which People Trusted Me More'}

The linked issues of navigating intercultural constraints and understandings - issues that rarely appear on the mainstream radaralso provide creative opportunities. In Shakthidharan's case, this can be likened to the persistent erosion to widen creative cracks against near invisibility. Shakthidharan acknowledges and draws on his relationship with members of his community but aims to create his own door to a wider audience and have his work critiqued, 'as art is intended to be, in the public realm' (Idriss 2018, 142).

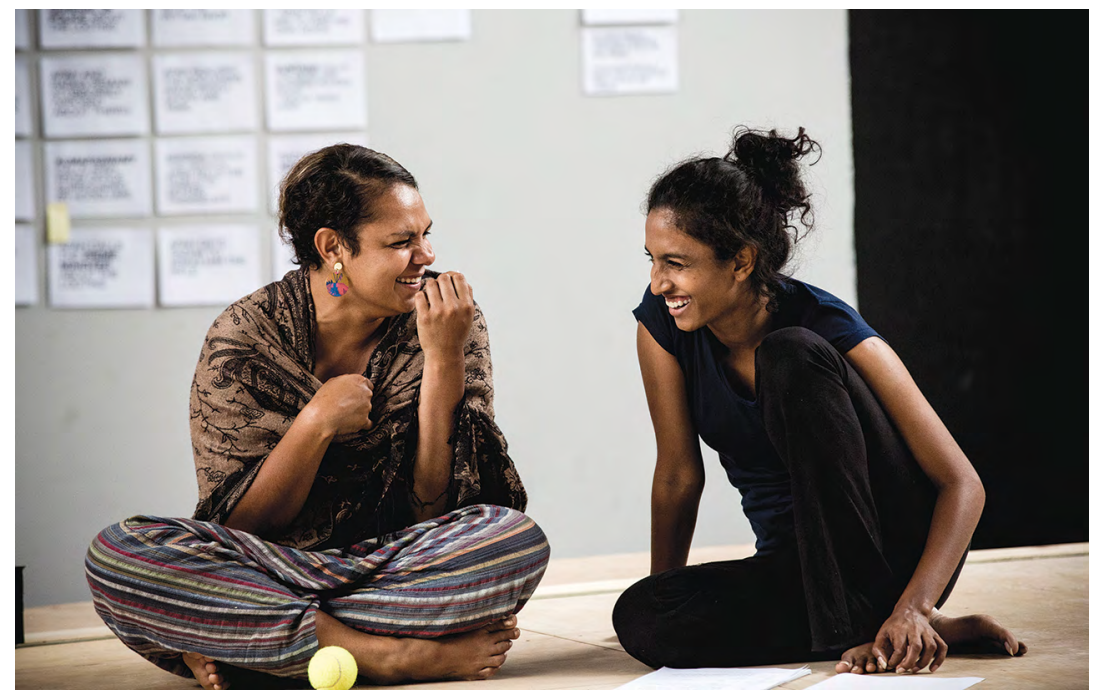

Image 9: Counting and Cracking, Belvoir Street Theatre, 2019

Photographer: () Brett Boardman

Shakthidharan's experience comes from pitching concepts to mainstream theatre companies and highlights issues he has faced as a contemporary artist (see Image 9). Despite having been awarded, and successfully delivered on, many grants, he perceives that he is still not trusted and therefore struggles to achieve his artistic vision:

As an individual artist, I would like a culture in which people trusted me more. People keep telling me I'm ambitious and 'that's an amazing idea, but it's going to be difficult'. But what they're saying is- your idea is different from my lived experience and for me to understand it, is difficult. And it seems really ambitious'. (S. Shakthidharan 2015, interview) 
This excerpt articulates the difficult relations with managers and directors of arts organisations and funding bodies that many NESB artists experience. The lack of trust congeals around the patronising turn of phrase that acknowledges Shakthidharan's 'amazing idea', yet, in the same breath, relegates it to the too hard basket. The issue may be one of ignorance on the part of mainstream directors. Regardless, Shakthidharan's concept is limited because they, the experts, 'know' what is achievable, and it would be too challenging to realise the project as he envisions it. Here, Shakthidharan describes a disconnect between his creative ambitions and the inability of mainstream theatre directors to adequately 'trust' his ideas. In this manner, Shakthidharan expands the context of cultural translation to include the ways he can translate himself into the broader theatre scene.

The 'disconnect' Shakthidharan experienced may also stem from the predominance of the Western canon and 'whiteness' in Australian theatre. When Lewis (2007) sparked controversy with her description of the lack of multicultural actors on Australian stages and screens, Meyrick (2007), a performing arts professor and experienced theatre academic, identified the issue as the source of content:

The crucial omission is playwrights. It is unremarkable that white writers write plays about white characters that are cast with white actors. That's not cultural conspiracy, just life. Non-white writers, if there were more of them, would write other kinds of plays, and casting them would involve different choices.

Meyrick dismisses any systemic issues as an overreaction ('not a cultural conspiracy') yet fails to suggest why there are not more 'non-white writers'. His comments arguably demonstrate the dearth of understanding NESB artists experience because of ignorance on the part of influential directors in the performing arts sector. To a certain extent, Meyrick's response typifies the prevalent 'laissez-faire' attitude towards NESB participation in the arts. He identifies the issue of there not being enough 'non-white writers', but relies on the vague notion that, in the undefined future, more 'non-white writers' may somehow find their way into the theatre pantheon. His comment is another variation on the it will take time' trope.

There is a profound ignorance of different cultural forms that manifests as lack of understanding. Mainstage companies, masking their ignorance of different cultural forms, revert to the label of 'too ambitious' to avoid dealing with their lack of understanding-their inability to process 
ideas that are outside their scope of experience. Similarly, 'ambitious' is a double-edged term often used in conservative areas of the arts to invoke issues of creative (and, therefore, assumed, box office) risk. Curiously, 'ambitious' is rarely used in its leadership sense of going beyond the usual. Artistic ambition evokes a challenge between the artist and their artform; however, it evokes a different set of challenges when ambition shifts to the relationship between the artist and the gatekeepers of organisations, managers, funding bodies and presenters. For Shakthidharan, being told that his concept 'seems really ambitious' is an early warning about the uncertainty of 'untested' (or untrusted) culturally diverse art product; it suggests an amorphous yet tangible barrier to creative innovators who reference aspects of multicultural Australia.

In contrast, an exemplary relationship of creative trust can be found in Koukias's Pentakostarion, commissioned by Jonathon Mills for the 2010 Federation Festival of Melbourne. The piece, which toured to the Chicago Cultural Centre, draws on the ancient liturgical languages of Greek, Latin and Hebrew through ritual chant and instrumental effects-handcrafted bells, several played underwater during the performance. Koukias (2015, interview) describes it as a: 'Beautiful commission. Beautifully funded. Jonathon gave me open slather. When I asked for a set of 61 bells in quarter tones, Jonathon being Jonathon said, "Yes, why not". Jonathon's response makes explicit the trust inherent in enabling rigorous intercultural creative production. A vibrant multicultural arts milieu would expand the opportunities for ambitious creative risk-taking by NESB artists.

\section{Critical Appraisal and Appreciation}

Critical appraisal assists in generating trust in an artistic work; however, many critics find engaging with multicultural content challenging. Part of the issue stems from the lack of dedicated writing on multicultural artists. There are more, albeit intermittent, pieces published on the politics of multicultural arts than about work by NESB artists. A successful essayist, Peter Robb (2012, 103), for example, in writing about GreekAustralian actor Alex Dimitriadis, adopts the attitude that if the content has a multicultural aspect to it, it must be 'worthy': 'For a film that was earnestly multicultural and calculatingly mass market, The Heartbreak Kid was surprisingly good'. 


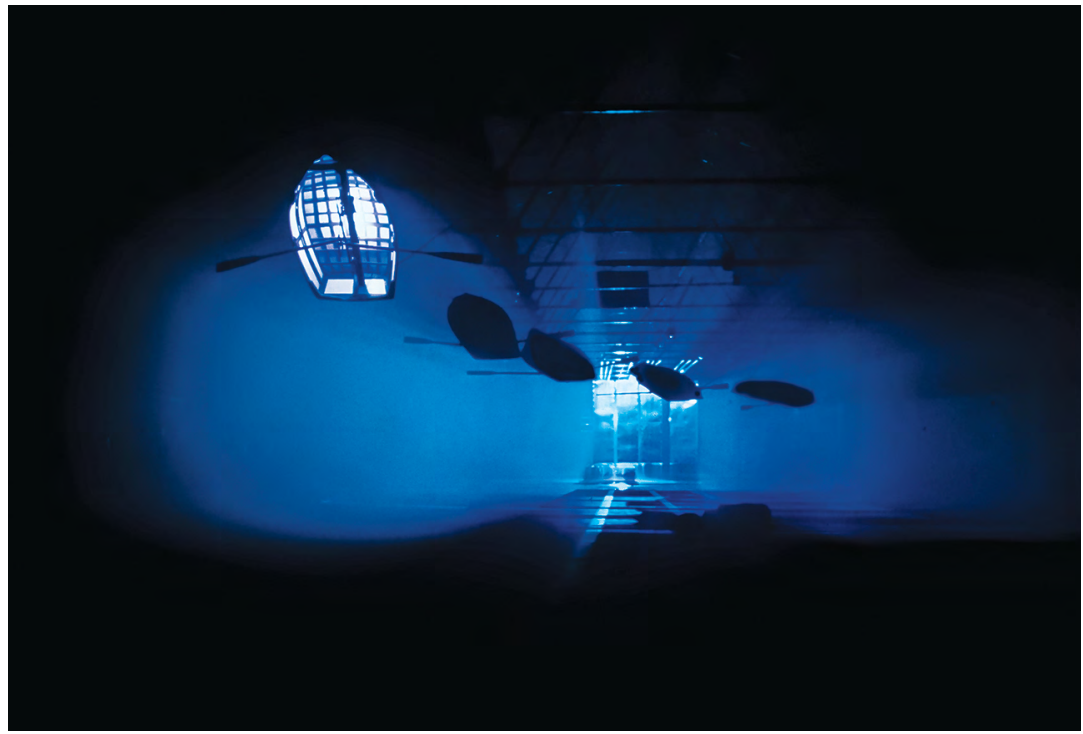

Image 10: Konstantin Koukias, To Traverse Water, 1995, Melbourne International Festival of the Arts

Photographer: Ann E. Wulff

The implication that a multicultural focus equates to being 'earnest' or politically correct and, therefore, not compelling or aesthetically valuable in its own right undermines public trust in the creative content. This approach to the critique of multicultural content applies across all artforms. For example, Koukias's To Traverse Water (1992) (see Image 10) was successfully received in Sydney and Melbourne, but the critics did not feel any need to do any research into the cultural milieu of the work: 'Deborah Jones wrote a wonderful review of it but said something like “it's all Greek to me"-which I found quite offensive' (K. Koukias 2015, interview).

A similarly dismissive comment in an otherwise supportive critique was made by a previous state gallery curator, Ian North, a 'trusted' commentator who expressed surprise at Valamanesh's early level of success:

Dwelling [1980] is worth emphasising not only as, in effect, Valamanesh's first major public sculpture, but because of its oddity. It made no concession to ameliorate its out-of-placeness or its unabashed multiculturalism, a term then coming confusedly into Australian currency. Remarkably, Valamanesh has persuaded his audience over the last three decades to accept the appurtenances and signifiers of Iranian visual culture in his work as he established 
his vision ever more firmly, operating not from ethnic ghettos but within the mainstream of Australian art. (North in Knights and North 2011, 7)

The view that Valamanesh would usually be considered as part of an 'ethnic ghetto' undermines his trusted status as an artist in the mainstream. Given North's influential position, his comments might have been more circumspect. Valamanesh questions whether there is 'such a closed shop? A closed community of so-called multicultural artists?' He reinforces the benefit artists receive from discussions around their work:

I've got enough good dialogue with people who look at my work, and people who write about or exhibit the work, that I feel like I'm not talking into the void. (H. Valamanesh 2015, interview)

This sense of connection to other artists and commentators is invaluable for the individual creative practitioner. I now turn to the ways in which creative leaders work with their personal supports to continue practising.

\section{Support through Networks}

Art as a 'tangible' career or work option is frequently discussed through an economic lens (Gerber 2017). However, the theme of support and networks identifies family matters, isolation, and access to sustainable and productive peer networks as constraints and enablers in the artists' experience.

\section{Family Matters}

Familial and cultural networks sometimes offer alternative relationships of leadership, trust and support beyond those purely within the arts sector. Two-thirds (66 per cent) of NESB artists place great importance on the support provided by their spouse or partner to assist their career; this is significantly higher than artists from English-speaking backgrounds (Throsby and Petetskaya 2017, 147). This suggests that there is a wide social and cultural context that the NESB artist must consider if they wish to develop and display creative leadership. The majority of the artists I interviewed had undertaken crucial negotiations with family members about entering the arts. Several postponed creative careers until they had completed family approved tertiary qualifications, usually in the fields of law, commerce or medicine. Permission from the family emerged as 
an important factor for second-generation NESB artists in their career path regardless of their ethnic background or class status; this mirrors the findings attributed to Arab-Australian male artists (Idriss 2018). NESB artists continue to seek and negotiate the conditional support of family:

My folks agreed that I could have a year to see if I could make some kind of a living out of acting. And I'm happy to say 45 years later there's still a job on the horizon. (L. Marinos 2015, interview)

Twenty-four-year-old Sean Ly went from being an unemployed 'bedroom musician' to becoming assistant director on CuriousWorks' feature film Riz by volunteering as a youth arts organiser for Fairfield Council. He has since enrolled in a tertiary and further education course to gain a youth worker certificate. Ly (2015, interview) has an instrumental view of the arts as a 'vehicle for us to promote our side of things' (see Image 11), yet senses that members of the Cambodian community in Cabramatta would frown upon a creative career:

Sections of my community would discourage me from arts. They don't see art as a true career. It's not a labour job, or it's not a desk job. It's not something tangible, but it's still a lot of work, and it tires you out. Like if that's what they see as proper work then the arts are definitely proper work.

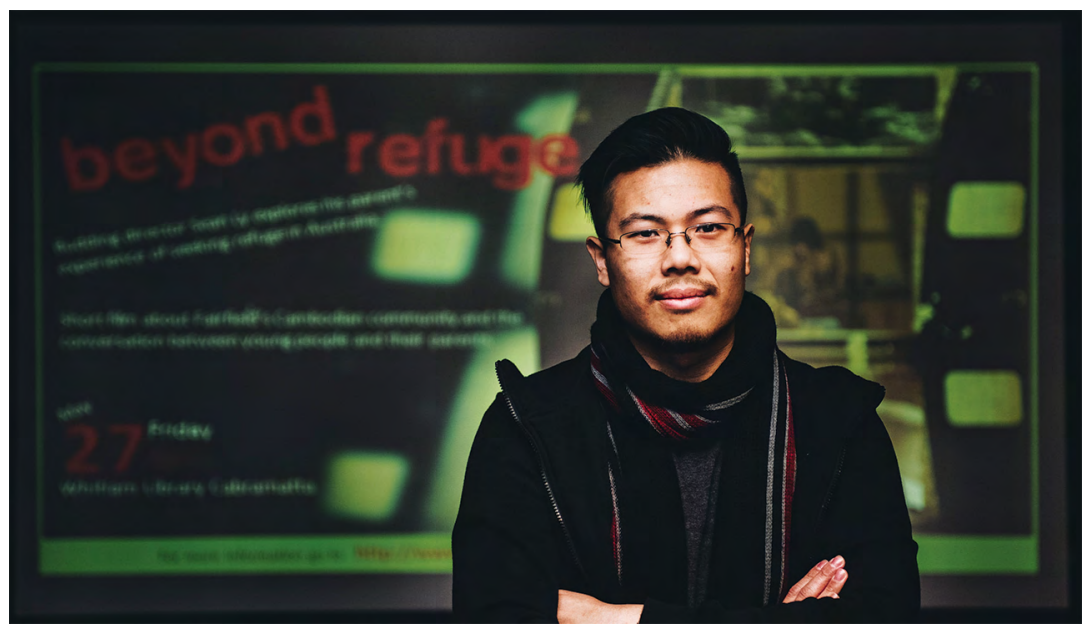

Image 11: Sean Ly (director and videographer), Beyond Refuge: Flashbacks, 2016

Produced: CuriousWorks 
As distinct from the perception (possibly) held by community members that artists live a free-floating 'bohemian' lifestyle, Ly appreciates the time and (often arduous) labour that artists invest in their work. This concept is not always considered by Arab-Australian artists from Western Sydney who see art as an income generating enterprise (Idriss 2018, 97). These findings can be applied to other ethnic groups as well. Ly was not encouraged to be an artist, and, having experienced 'long periods of unemployment', he will no longer pursue a full-time arts career. Instead, he prefers to be involved in the more acceptable community sector, because, as he explains, 'that's where I want to make a career to support myself in the future'. Working within a local council has its own challenges but carries the allure of employment that is more stable than the arts.

To facilitate arts projects as distinct from making them is a frequent route for practitioners and partly explains the low numbers of professional NESB artists. The low level of arts-related employment for NESB artists is also reflected in Ly's decision to become a council youth worker. This pragmatic response to the vagaries of a creative career is understandable and contributes to their low representation in the arts.

The issue of family support also cuts across class. Anna Lau struggled to gain permission from her mother to be a playwright. Lau is a young woman of Taiwanese-Malaysian parentage who arrived in Australia when she was one year old. She, like most of her friends, gained entry to study law or economics; however, she negotiated to study international relations because of the 'proximity to people's stories'. Ashamed of her Chinese background as a schoolgirl, Lau exemplifies Ang's $(2001,51)$ insight that 'if I am inescapably Chinese by descent, I am only sometimes Chinese by consent':

I don't identify with migrant experiences because, having grown up here, that's never been my story. Asian arts tend to be suitcase stories rather than second-generation arts, so I feel like there's a lot of creative leadership needed to change arts relevance to me. (A. Lau 2015, interview)

'Suitcase stories' of unknown arrivals in a strange landscape were a feature of Australian representations of migrants in the 1980s. By differentiating herself from her parents and their 'suitcase story', Lau foregrounds the intergenerational friction of different cultural experiences. She persisted in an arts career after seeing inspirational theatre, even though it was not her milieu: 
It is hard to believe that Asian families would send their children to a specialist arts high school. I would have loved to continue Visual Arts and create a major work. I would have loved to attend a Performing Arts School. But, it would never have been my choice. Perhaps this has something to do with the lack of AsianAustralian artists on our national landscape. (Lau n.d.)

Linking the lack of family encouragement to the lack of Asian-Australian artists highlights two vicious cycles that reinforce the lack of cultural diversity on stage. The under-representation of Asian-Australian artists conveys the difficulty of a career in the arts and the low number of role models reinforces the low take-up. The arts are considered a poor career choice due to the lack of reliable income and low social standing. This, in turn, discourages the uptake of arts training, thereby perpetuating the low numbers. It is claimed that Chinese-American parents lack of support for 'risky' creative careers is not solely motivated by financial reasons, but because such careers:

Involve subjective evaluation, thereby making their children vulnerable to bias. By contrast, careers in medicine, engineering, law or pharmacy require higher credentials which protect their children from the usual types of discrimination. (Lee 2014)

This subtle reason extends the value that migrants place on education to increase social mobility. The careers favoured by parents are seen to reduce the economic and cultural vulnerability of their children. This perception may alter with subsequent generations and as the benefits of the arts and creative thinking become increasingly recognised.

Shakthidharan's Tamil Sri Lankan background also instils self-reliance and economic responsibility (see Image 12). His mother is a performer and choreographer who did not want him to select the arts because she was keenly aware of their lack of stability:

In my community, your own life is not what should come first. My uncle and anyone in my family thought it was stupid to get into the arts because it's a pretty dumb place if you're trying to look after a number of people financially. (S. Shakthidharan 2015, interview) 


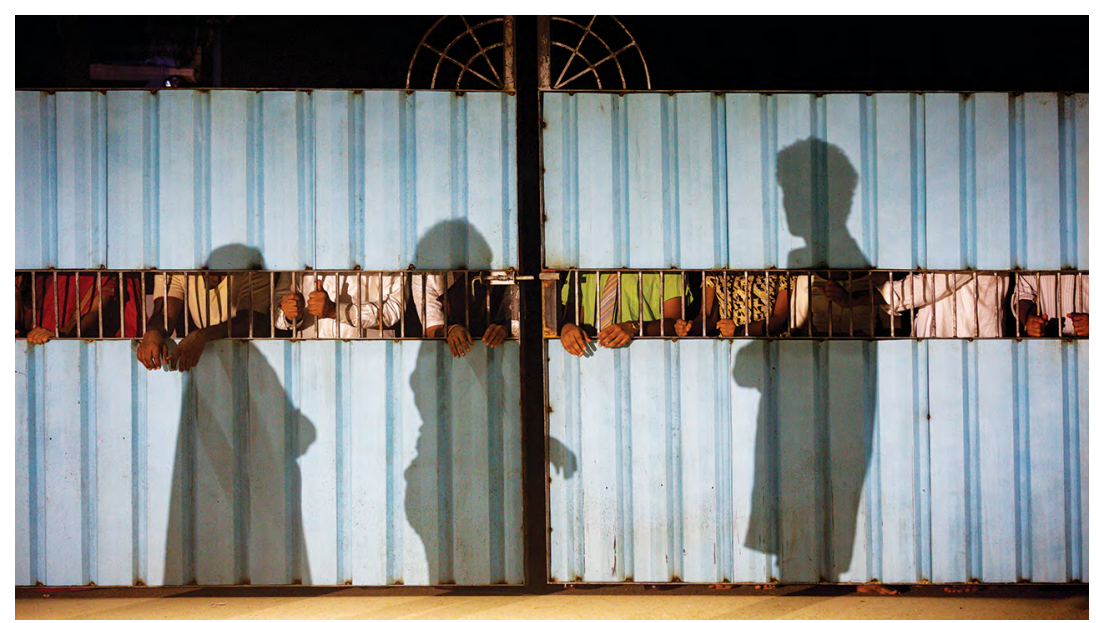

Image 12: Counting and Cracking, Belvoir Street Theatre, 2019

Photographer: (c) Brett Boardman

Shakthidharan managed these competing expectations by covertly enrolling in a university media degree as a first step on the path to realising his vision to get 'other' stories told. The financial constraints placed on him were ultimately beneficial, as CuriousWorks began with an independent (of government) income stream to deploy as the company saw fit.

To pursue an arts career in these situations hints at personal struggles that undermine or compromise family trust in some way. To undertake a family approved tertiary degree and/or find a degree that is personally (and creatively) satisfying is an early sign of the persistence required to work as an NESB artist. Such negotiations develop relational leadership skills through the management of negotiations, acknowledging the role of relationships beyond the drive for an individual artistic career.

\section{Isolation: 'I Thought They Were Only My Issues’}

Isolation was a topic raised frequently by the artists I interviewed. Likewise, 50 per cent of NESB artists from Western Sydney identified more opportunities to meet other artists as their most important need (Stevenson et al. 2017, 54). One creative leadership consequence of this is that those artists who recognise this need may draw on it to create networks with other artists for social and creative support. This may be one area that distinguishes NESB creative leaders, as it shows the ability to 
use friction creatively, changing adversity into an advantage. An isolated artist cannot share their concerns and, therefore, often internalises a sense of inadequacy:

Looking back, I thought they were only my issues. I didn't realise it was systemic and what that means in terms of policy and infrastructure. It's very isolating. It diminishes your belief in what you think you can do. I think that's why I left [Australia]. I saw it as being very narrow visioned. And coming back I realisedsomething's really wrong here. How is it that it can still be this hard? Is it still me? (A. Paul 2015, interview)

These feelings are not easily expressed in public forums and, therefore, rarely get aired. Dancer, actor and choreographer Annalouise Paul is describing a milieu that does not support her. Having worked successfully overseas for many years, there is poignancy in her question- is it still me?' This highlights the need for artists to adapt, adjust and create their own milieu. A productive milieu implies the existence of structures that enable risk-taking and supportive contexts to flourish (see Image 13).

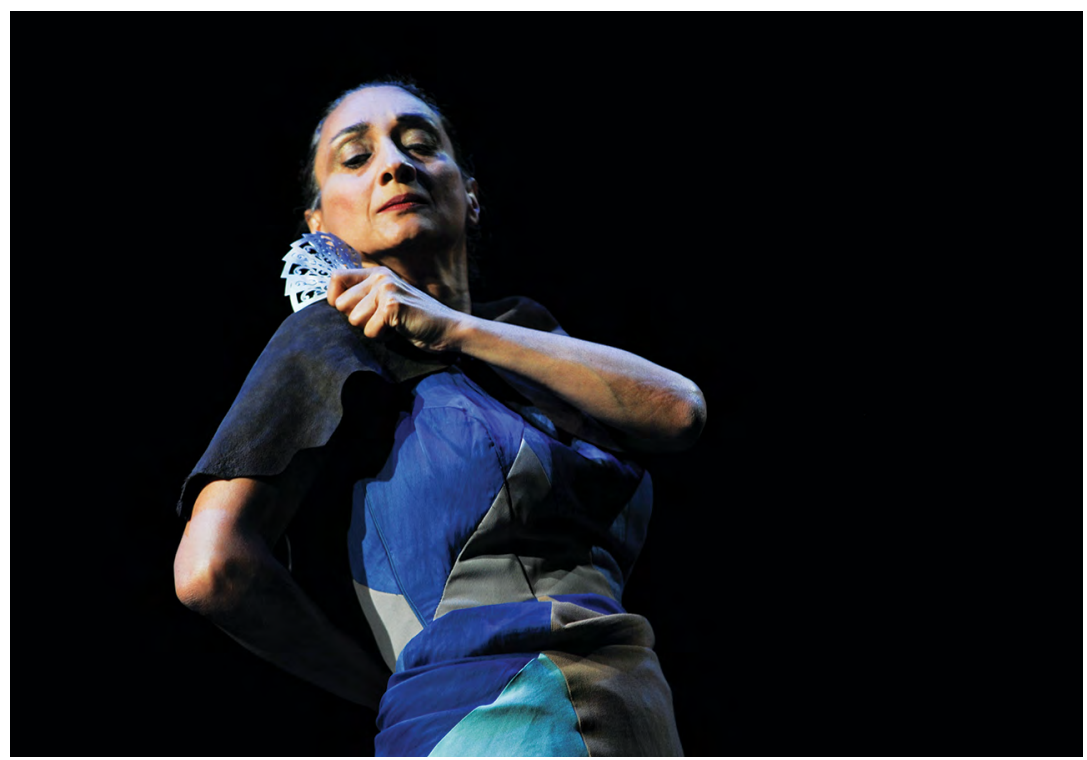

Image 13: Annalouise Paul, Forge, 2016

Photographer: Heidrun Lohr 
Anna Lau experienced a different type of professional isolation when she finally began playwriting. Her creative endeavour became a point of difference between her and her Asian-Australian friends who all studied commerce, law or medicine and were not sure what playwriting was or why anyone would want to do it. Lau felt like 'a pioneer because I didn't know anyone who did it, except for me'. As an artist-in-residence at Shopfront Theatre, a youth co-op theatre in southern Sydney, she found the first stages of the creative process completely strange:

I just felt like such a black sheep. Like the artistic director and the other artist-in-residence would just sit down and say 'For today's session I'm just going to play'. And I'm like-what is this concept of play? [laughs] I want to sit down and plan! (A. Lau 2015, interview)

Lau had not been exposed to artists. Until that point, her career path had been based on action plans, focus and deliverables. While these are also necessary for a career as an artist, they need to be balanced in proportion to the creative process. To Lau, the idea of 'play' was indulgent, but it was an indulgence with which the other resident was clearly familiar. Here Lau experiences conflicting emotions. She expresses pride and confidence as a 'pioneer' alongside rejection and isolation as a 'black sheep' in her first foray into the world of playwriting. The way an artist responds to these scenarios suggests the friction of 'breaking into', which paves the way for them to become creative leaders. Lau's isolation takes the form of 'cultural remoteness' (Idriss 2018, 71), whereby her upbringing and acculturation did not match the expected behaviours and styles of her new creative milieu. Role models may help to overcome such remoteness.

\section{Role Models: 'They Get Proud by Association'}

Exposure to role models instils confidence. This can happen within a small experimental arts scene, with super 8 film and tape loops, as media artist and cultural producer Panos Couros (2015, interview; 2017) explains:

There was another Greek guy there who was the most articulate person I'd ever met. He became a role model because I thoughtwow, how can someone from our cultural heritage be that lucid, articulate, and intellectually challenging. 
Thirty years later, the same proud moment of recognition through ethnicity continues to occur. Valamanesh (2015, interview) recognises the importance of leading by showing:

I go to high schools to talk where there's lots of young Iranian or Afghani. I can speak the language. They get really excited to hear that even someone from Iran has made it [as an artist] here. And they suddenly put their chest up, 'Oh he's from Iran. I'm from Iran'. They get proud by association.

Small moments such as these can be significant in the future choices of young people. Despite Valamanesh's claim that he has been included in the arts in Australia, he hints at the students' sense of isolation when he uses the word 'even', suggesting that it is rare for someone from Iran to 'make it' (see Image 14).

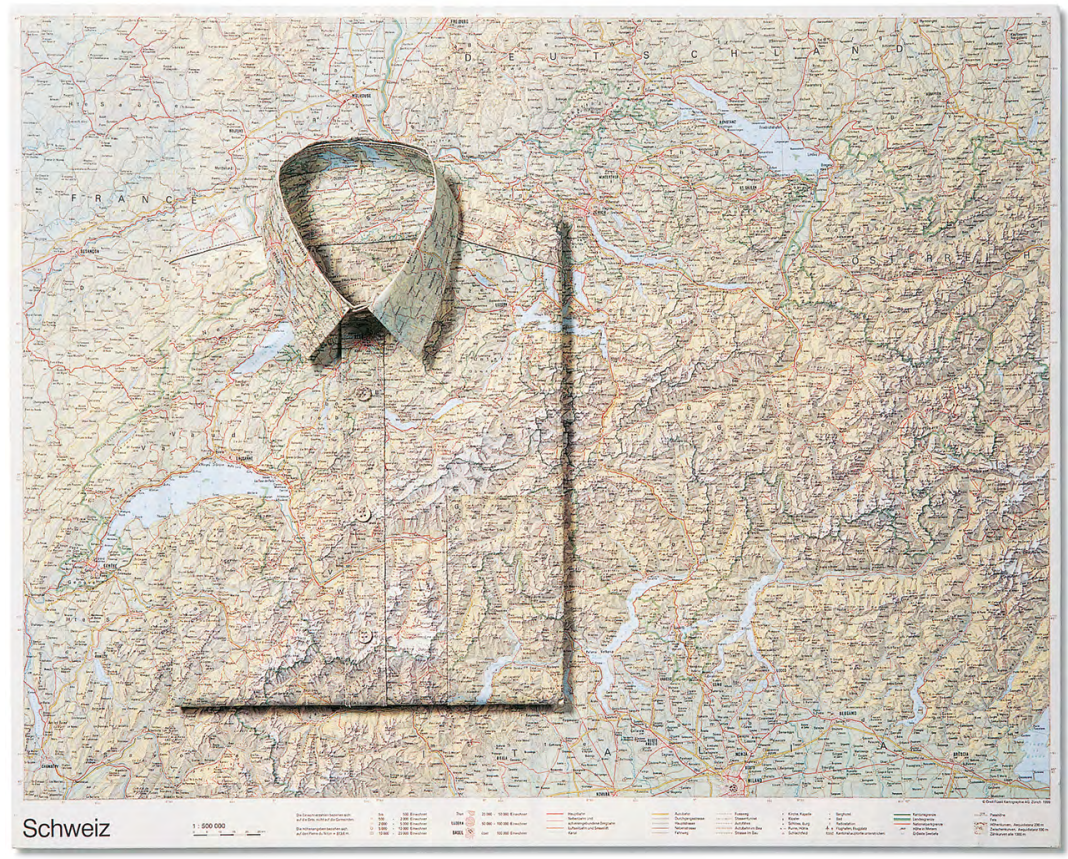

Image 14: Hossein Valamanesh, Untitled Map, 2002

Paper map on cotton, multiples of four, $62.3 \times 77.5 \times 7 \mathrm{~cm}$

Private collection, Adelaide

Photographer: M. Kluvanek 
All artists want exposure for their work, yet access to extended networks and avenues of support to facilitate that exposure can challenge the resolve of the artist. The more influential arts spheres, such as 'the big end of town' of the major performing arts companies and the funding bodies, can be difficult for NESB artists to access, making the forging of a trusted profile in the arts also difficult. Shakthidharan wants to be the one who is trusted with the financial resources to see his theatre work to fruition. NESB artists' experiences suggest an image of different planes of access that tend to operate independently and not readily engage with each other, but rather slide over one another. The mainstream is comfortable in its place in the central current and, to some extent, the NESB artist is comfortable in the tributary of the community arts worker. It is more likely to be the independent NESB artist who interrupts the current of the mainstream by their creative leadership, whether through recognition of their artistic work, developing networking capacities with other artists or negotiating productive working relationships across the arts sectorsall of which play into an improved multicultural arts milieu.

\section{Productive Peers}

The support of peers and networks is essential to the systems that independent artists create around themselves to shore up their precarious existence and art practice:

Precarity is the condition of being vulnerable to others. Unpredictable encounters transform us; we are not in control, even of ourselves. Unable to rely on a stable structure of community, we are thrown into shifting assemblages, which remake us as well as our others. (Tsing 2015, 20)

Tsing elucidates precarity beyond unequal economic scenarios and emphasises the productive connections that can potentially occur between those who are different to us. The existence of networks that build trust across those interfaces contribute to successful multicultural art projects and milieu.

Lau is a confident young woman, but her experience of isolation extended through each stage of her forays into playwriting. Unlike the other artistin-residence, she had no one to call on when it came to finding performers to read her script: 
All her friends were actors and all part of that industry. She just had to put it on Facebook to get like a hundred responses for actors. None of my friends are from that industry. I asked-do you have anyone left over that I could use? (A. Lau 2015, interview)

This tale indicates that Lau had neither the social, professional nor cultural contexts to activate her presence in the arts. Her determination to supersede these constraints is commendable. Shopfront is a workshopbased, performing arts organisation for young people in southern Sydney. It is considered an accessible route for young playwrights; however, it appears to have been unable to stretch enough to incorporate Lau adequately during her residency there 2014. In 2017 only two NESB artistic facilitators could be identified from the pool of 16 then on their books, limiting their ability to deliver on their rhetoric of access (Shopfront 2017). It was not until Lau attended programs developed by CAAP that she met artists with whom she could identify as mentors and peers. These examples identify a 'pushback' sensibility of the artist who, regardless of the nature of the gesture, contributes to a multicultural arts milieu. The artist must also push forward.

\section{Persistent Creativity: Mother Tongue}

Mother Tongue is a long-form choreographic work that presents an 'eloquent dance-poem on war, cultural tolerance and healing' (Paul 2018). After being initiated by Annalouise Paul in 2007, a 'pilot' was finally presented at Bangarra Theatre, Sydney, in 2014 (see Image 15). In 2020, the work still waits for its premiere. This process over many years exemplifies the persistence required of a creative leader through the iterations of creative investigation and logistics that should lead to a public presentation. The independent artist must be resilient; they must be able to reaffirm trust in themselves and their creative engagement with their work. The account that follows describes the trajectory of an intercultural work approximating an 'everyday' sense of the work involved. The use of 'everyday' needs qualification because the artistic result is not of the everyday; it may draw on the everyday through the proximity of diversity, but art is an abstracted and condensed expression of everyday encounters. Mother Tongue elicits how creative leadership responds to the barriers faced in that process. 


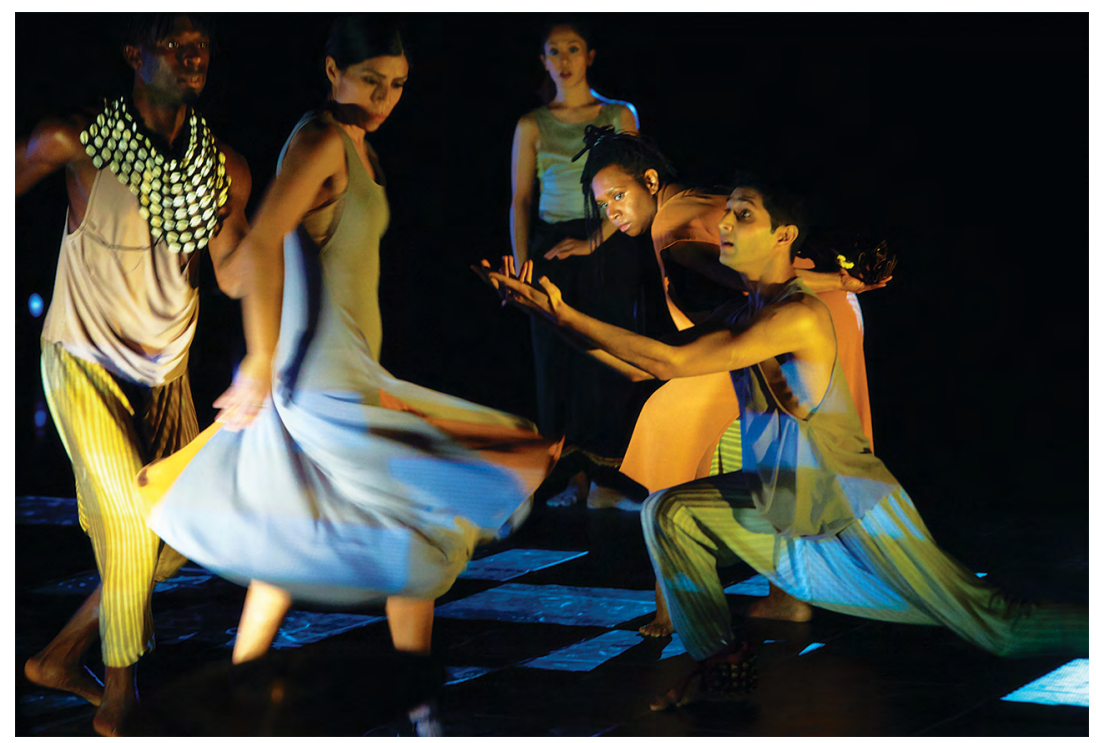

Image 15: Annalouise Paul, Mother Tongue, 2014

Photographer: Shane Rozario

I selected Paul as an exemplar because of the challenges she experienced at every turn to produce a major performance work as an independent practitioner with limited infrastructure support; because her extensive performing career includes acting, dancing and choreographing; and because her efforts demonstrate agency and creative leadership. Beyond her individual practice, her ambition is to establish the first Australian intercultural dance company, which would benefit other artists. Her experiences provide an opportunity to gauge the application in Australia of UNESCO's 'culture cycles', the value chain encompassing education through to distribution (Mar and Ang 2015, 7), and highlight potential interventions relevant to NESB artists.

Paul's intercultural practice began with her choreographing and performing a 'fusion' of contemporary and flamenco dance, and she continues to refine what it means to produce intercultural dance by working with other performers. Mother Tongue was the third part of a trilogy supported by Parramatta-based Western Sydney Dance Action (FORM Dance Projects n.d.-a). This dance organisation, now FORM Dance Projects, was part of the 'culture cycle' as it provided modest financial and administrative support in the crucial early stages of Paul's process. Their description downplays her challenges: 'Her enduring fascination with other cultures investigated questions of identity and intersections between cultures through cross- 
cultural dance/music relationships' (FORM Dance Projects n.d.-b, 9). This text points to the complexity of intercultural art through the use of floating signifiers - symbols or terms open to wide interpretation that rally people around a commonly understood issue. The term 'questions of identity', for example, rallies those who see themselves in the minority, while 'cross-cultural' elides the issue between crossing ethnic identity and cultural forms (e.g. contemporary and traditional music or dance). This collision of terms occurs within the arts because of confusion between ethnic identity as subject and the different cultural forms of art. Paul is positioned as a cosmopolitan art connoisseur whose source material 'fascinates'; her work is thus presented as a pleasurable representative of multicultural Australia. The risky result of her 'fascination' could be critiqued as part of the 'discourse of enrichment', whereby cultural engagements (in both senses of the word), including those of food and dance, take the form of a multicultural fair (Hage 2000, 119).

The various 'ethnic' stalls of the fair are perused by, and enrich, the 'real Australians, the bearers of the White nation' (Hage 2000, 118). Paul's position can be considered within the contemporary and changed version of the fair, whereby migrants (one assumes non-English migrants) also want to be enriched but are 'blocked' by the white multicultural fantasy that aims to maintain a central role in apportioning access (Hage 2000, 118). As we have seen, this controlling role produces a barrier for artists in terms of their access to bureaucratic and mainstream organisations. Hage's analysis falters when applied to artistic attempts to engage with cultural diversity, as he digs through layers of cultural mistrust. Art requires that mistakes are able to be made. Faltering also produces moments of vulnerability for the artist. In this faltering, the artist may demonstrate creative leadership. Such vulnerable processes suggest use of the sociological term 'quotidian transversality', in which opportunities from the everyday, or the quotidian, open up and reconfigure through interchange or the 'transverse' (Wise 2009, 23). Drawing on Cockburn and Yuval-Dais (1999), Wise $(2009,23)$ claims that the transverse provides an opening that goes beyond the hybridity of exchange, or assimilation of merging, and is therefore useful to the arts:

[Transverse] highlights how cultural difference can be the basis for commensality and exchange: where identities are not left behind, but can be shifted and opened up in moments of nonhierarchical reciprocity, and are sometimes mutually reconfigured in the process. 


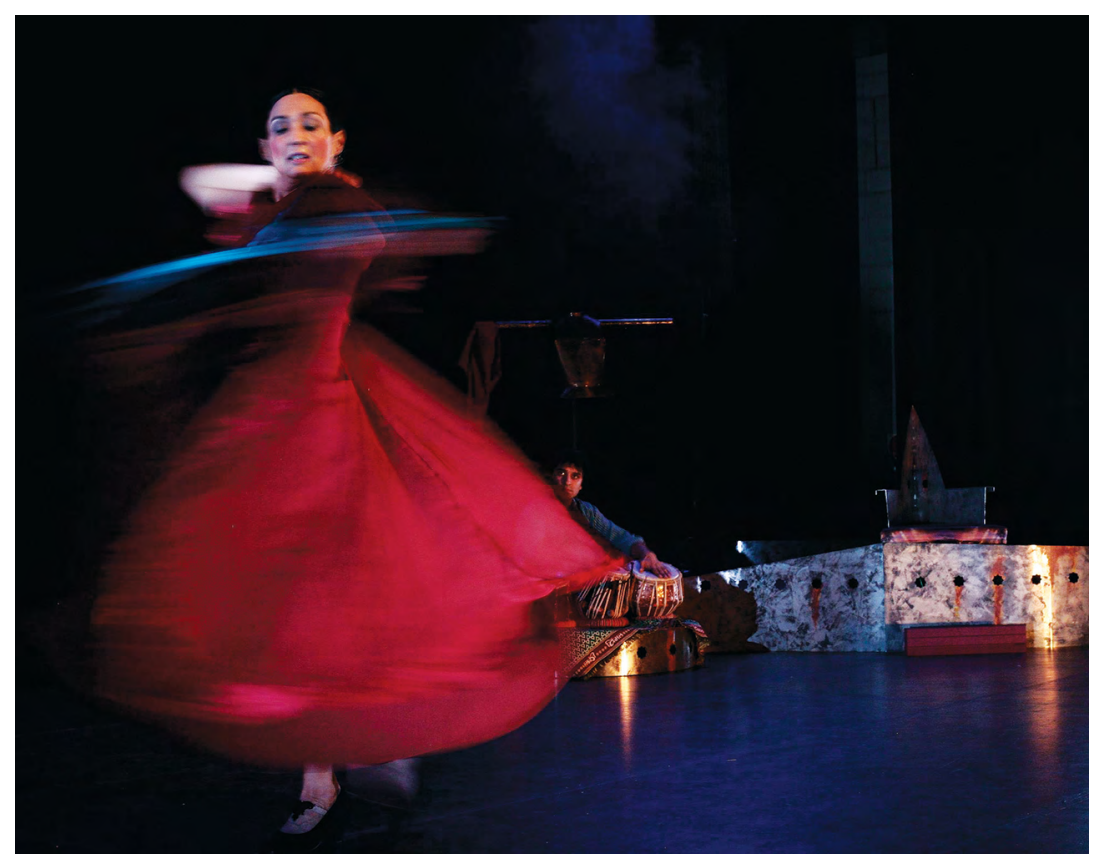

\section{Image 16: Annalouise Paul, Isabel, 2008}

Photographer: Shane Rozario

Such moments of reciprocity can become available in the tangible yet fleeting forms of performance. In the first of Paul's trilogy, Isabel, flamenco dance and tabla percussion explore Queen Isabel of Spain's notions of power and colonialism in 1492 (see Image 16). The second part, Game On, broadens the historical approach to produce a conversation between a tabla player and a contemporary dancer in which Paul questions 'how extreme cultures coming together can communicate'.

Everyday cosmopolitanism is evoked by a 'conversation' and is complicated when held between 'extreme cultures'. Paul articulates an inherent, almost abrasive, friction that she engages with on a creative level. Each artist challenges the other in both tradition (flamenco and tabla) and form (dance and percussion). In this example, the transverse shows that the interchange causes friction: it is not 'smooth' (Carmichael 2011, 65). Different creative knowledge sets come together to challenge the performers who take a risky path because the creative results are unknown. Even as choreographer, Paul cannot control the creative 'conversation'. The physicality of the performers highlights the dynamic interaction on stage and exemplifies the creative use of 'unpredictable interfaces' that arise from multicultural 
Australia (Mar and Ang 2015, 8). Game On is bicultural and, therefore, more easily grasped by an audience. The interface through the individual forms of flamenco and tabla are reasonably familiar to Australians. The unpredictable aspect is that they are not usually in the same performance. As a bicultural performance (which, in fact, is what most 'multicultural arts' tend to be), Game $O n$ takes an incremental step towards establishing a multicultural arts milieu.

Paul approached the multicultural arts touring group kultour for touring support to widen the audience for Game On, only to discover that she was excluded because there was no NSW member. This realisation took her into the realm of arts politics. In 2011 she established Groundswell, a lobby group to generate support for the re-establishment of a NSW multicultural arts organisation (Paul 2010; Koubaroulis 2014). Over the next five years her arts practice continued, albeit at a much slower pace. This deviation is not uncommon among NESB artists who find they must be politically active to achieve structural change to improve their pathways.

Proceeds from a school's tour funded Game On at the Sydney Opera House. In 2011 Arts NSW and the Department of Foreign Affairs and Trade toured it to India whereupon it won two awards: Australian Arts in Asia and the Export Award. On the back of that success, Paul began work on Mother Tongue, a 'body percussion' piece with Bobby Singh, Miranda Wheen, Greg Sheehan, Albert David, Latai Taumoepeau, Lucky Lartey and Shruti Ghosh. The work is concerned with reconciliation and understanding between cultures. Paul (2015, interview) kept coming up against controversy and lack of appreciation or understanding of her intercultural style and the content:

There was controversy about why I wanted to use six, seven, eight different cultures; why I was using Albert David, an Aboriginal artist and why body percussion. My answer was why not? The Australia Council wanted to see their familiar styles of contemporary dance, and couldn't imagine how it was going to look. A dance organisation said it was going to look like a variety show. At the other end of the spectrum, presenters were saying 'just put them all onstage together and jam'. There was a lot of extreme views about how culture should come together-so the smash-up idea of jamming and fusion: do whatever and then the elitist: 'is it going to look messy?', the aesthetic around it was in question. 
The use of the adjective 'extreme' was personal this time, as it concerned Paul's aesthetic choices. This was her stepping towards a multicultural and intercultural (in both social and cultural meanings) work. She was offended by the presenters' suggestion to 'jam', a loose technique of turn-taking associated with non-classical music, because it devalued her skills as a choreographer. Such responses bring into sharp relief the lack of support for risk-taking. Luhmann's $(2000,94)$ definition of trust as a 'specific solution to risk achieved within a familiar world' applies here. The systems that fund development and presentation were not prepared to be part of Paul's solution. They did not trust her approach. She was not part of their milieu.

Mother Tongue fell prey to the 'yo-yo' funding of small grants. Frustrated that the project was not developing, the artistic team suffered a mini crisis, leaving Paul at a crossroad. She no longer knew 'whether it's meant to be a narrative or more abstract, and it went belly up for a little while'. A Bundanon residency provided the necessary creative space. Paul received some funds from Arts NSW and Bangarra provided a venue. Paul was proud that the dancers could be paid from box office sales, crowd funding and the bar. An exit survey and 'vox pop' with the culturally diverse audience members showed that most felt it could 'really go places' and 'it was ex-cell-ent' (Paul 2015).

Limited critical engagement by the mainstream media means that NESB artists often have to rely on niche funded arts magazines such as the now defunct RealTime for critical appraisal. In the case of Mother Tongue, the reviewer invoked a clumsy metaphor of a wildlife park:

Kinetically, Mother Tongue is a sculpture park of rich, exotic forms coming from Torres Strait, Chile, Indonesia, West Africa, Brazil and India. Since Paul does not innovate from appropriation, strict fusion or exploding traditions, and maintains the integrity of colliding cultural forms, her seeking 'new choreographic futures' for intercultural dance proves an admirable challenge. There are moments in Mother Tongue when movement and gesture founded on the primordial geometries of collective motion and sound sublimely commune towards a unique horizon. (McNeilly 2014, 33)

To arrive at that sublime point took seven years work and relied on multiple sources of inspiration, resources and income. Touring is the next phase in the 'culture cycle'. kultour had ceased touring culturally diverse work by 2014. The mainstream organisations such as Performing 
Lines and events such as the Australian Performing Arts Market that were expected to take on that role were guarded in their response to Paul's work. Paul was warned by the project director of the International Network for Contemporary Performing Arts, the Australia Council-funded network that matches the 'market development aspirations of Australian artists with opportunities and resources' (Australia Council n.d.-b), that:

'You're ahead of your time. Australia's never going to get it, get out'. And I just thought-I don't know if I'm ahead of my time or Australia's just way behind it. (A. Paul 2015, interview)

The project director's comments do not show leadership: they are another way of saying 'too ambitious'. Abrogating the responsibility to champion ambitious projects, the project director shut the door on Paul's aspirations with alacrity. Mother Tongue highlights the gaps in the full application of UNESCO's 'culture cycles' (Mar and Ang 2015, 8-15), notably the riskaverse nature of support for the arts by funding bodies in development, presentation and national and international marketing. Paul's project is multicultural in content and concept; it generated positive audience responses and delivered a professional outcome, mainly on a volunteer basis over several years. Its processes were only challenged when intersecting with the arts 'industry'. The diverse cultural and creative backgrounds of the artists underpinned Mother Tongue, enabling the performance to work 'across cultures' and develop 'cross-cultural partnerships' (see Image 17). The full spectrum of the 'culture cycles' was hindered by concerns expressed by sector gatekeepers who, confronted by the concept of Mother Tongue, signalled their reluctance to support and program the work. The symbolic role and reception of this performance are also part of the 'culture cycles'. The audience response to Mother Tongue reinforced its relevance, but only after surmounting the barriers presented by the funding agencies and dance experts to locate that audience.

As mentioned, Paul's ambitions go beyond her own practice. Demonstrating her support for a multicultural arts milieu and leadership role, she sought partners to establish the first national intercultural dance theatre company in Australia, similar to the Indigenous and internationally acclaimed Bangarra Dance Theatre:

It will be multi-nation, here's that word-multicultural. Multiple cultural expressions. As a creative leader in that role, I would seek advice and support from those around me; it's about having multiple viewpoints that are working towards the one thing. (A. Paul 2015, interview) 


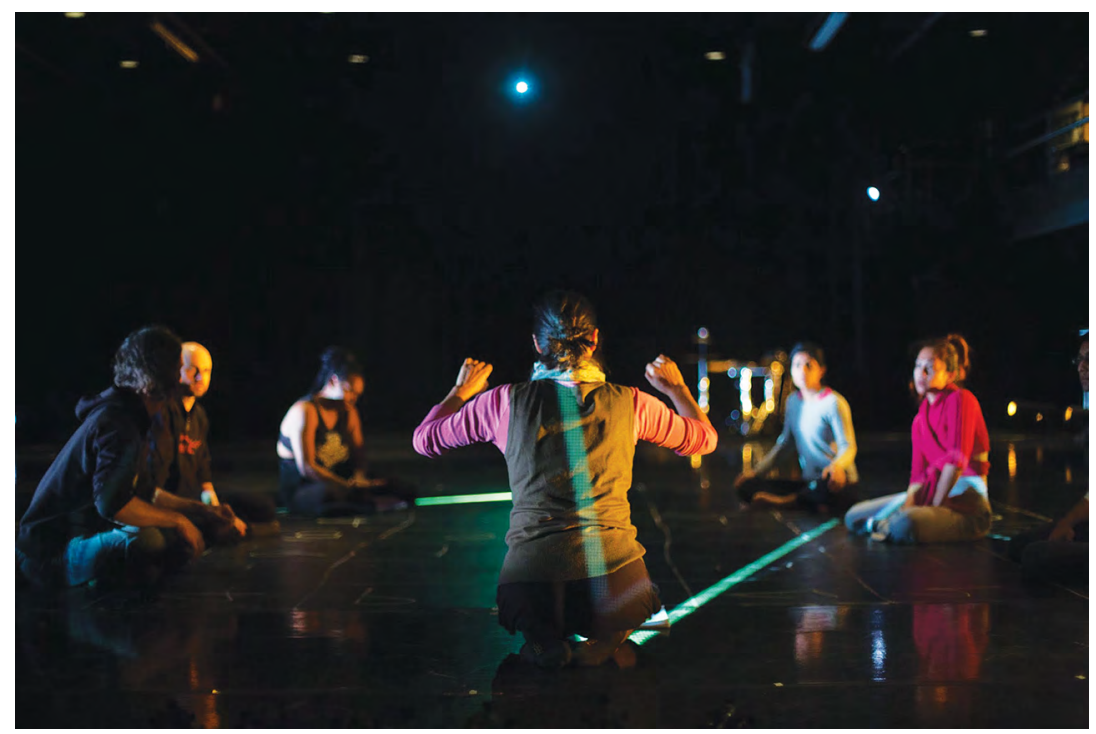

Image 17: Annalouise Paul, Mother Tongue, rehearsal, 2014

Photographer: Shane Rozario

\section{Creative Leadership}

Analysis of the paired themes of friction and creativity, trust and legitimacy, and support and networks demonstrates the constraints and opportunities that NESB artists can experience in pursuing a creative career. The artists in this study demonstrate the characteristics of creative leadership that inform and draw upon multicultural Australia, and articulate how best to creatively, politically, financially and pragmatically navigate, and intervene, in the arts system:

Creative leadership now is about finding and working with individuals within the systems who have a mutual vision with you. Finding the resources to do that, because that's separate to project funding. (S. Shakthidharan 2015, interview)

Creative leadership is about producing and presenting work that is relevant or, as Lau (2015, interview) put it: 'Being able to create something that resonates with people. I haven't seen anything in Australian arts that resonates with me'. Lau was not alone. Only one interviewee identified a recent Australian artwork as satisfying, although many could provide an international example. Creative leadership for a younger, second NESB 
generation is based on a different set of experiences. A daughter of migrants, Lau rarely sees her generation presented on stage and screen, an exception being Benjamin Law's Chinese-Australian sitcom The Family Law, which screened on SBS television in 2016.

For Nguyen (2015, interview), creative leadership changes perceptions and enables a closer appreciation of people in new and contrasting situations:

Recently Dad went to the Fringe Festival. I cannot imagine any other Asian parent in their sixties going to a Fringe Festival. That is a good story. That is about creating contrast and clashing of different cultures, and seeing the result.

Nguyen contemporises his father and is keen to articulate new narratives of someone who is open to a new life. He places his family inside an arts scene (which he considers unusual and potentially risqué) and views the creative potential as 'clashing' to produce unexpected outcomes:

It's about taking risk. It's about speaking out. I'm an advocate as well as an artist, by just speaking out. It's about taking people with you and adding value to something that's already there. It's about pushing things beyond what's expected. (A. Paul 2015, interview)

This is a direct example of creative friction. For Paul, there is a political edge to leading creatively as well as going beyond the expected norms. Valamanesh and Koukias are among those artists who found their creative edge via their ethnicities in relation to the Australian context. Valamanesh creatively leads by doing to just show that it can be done, from my honest view as an artist'.

\section{Conclusion}

NESB artists navigate the friction between competing aspects of innovation and the maintenance of cultural heritage. Innovation is a synthesis of fresh ideas into new forms of production that resonate within contemporary society. Cultural heritage is a 'collective memory made tangible' that surfaces through forms of 'expression, maintenance, representation, recognition and renewal' (Anheier and Isar 2007, 30). These characteristics are frequently positioned as mutually exclusive binaries for multicultural arts practices. However, I have shown the ways 
in which NESB artists push this binary 'beyond what's expected'. By doing so, they demonstrate creative leadership through the persistence required in the face of stereotyping barriers. The artists in this study demonstrate the principles that promote diverse cultural expressions by producing work that comes from 'working across cultures' and being able to develop 'cross-cultural partnerships' (Mar and Ang 2015, 8-10).

The majority of the artists in this study faced challenges in the broader 'industry' aspects of success, particularly in relation to being programmed, presented and promoted. They all support and recognise the contribution of NESB artists' work to Australian society, despite the lower rates of financial support from state-sponsored arts programs. The income gap from their art practice is lessening; however, the number of professional NESB artists is half that of NESB employees in the overall workforce (Throsby and Petetskaya 2017, 142). The arts industry's resistance to include NESB artists as 'leaders', the paucity of resources for culturally diverse infrastructure and negative perceptions as to the value of an arts career in Australia are just some of the reasons for the glacial pace of change.

Nevertheless, some NESB artists have developed and maintained careers in the face of such odds, demonstrating creative leadership through their agency within the Australian arts sector. These artists possess the ability to cross between, and adapt to, different cultural spheres, including the possibility of communication across intergenerational changes; a practical understanding of the delicate tactics and strategies required to navigate their immediate cohort of friends and family, as well as the arts sector in its myriad aspects; being prepared to participate in the inevitable link between arts and politics that will confront them at some point, in particular issues of inclusion in the arts; and being prepared to push the boundaries of the canon and to creatively adapt aspects of their cultural heritage. These adaptive elements use relational, distributive and charismatic leadership modes. 
This text is taken from Creative Frictions: Arts Leadership, Policy and Practice in Multicultural Australia, by Cecelia Cmielewski, published 2021 by ANU Press, The Australian National University, Canberra, Australia.

doi.org/10.22459/CF.2021.04 